\title{
Volumetric muscle loss leads to permanent disability following
}

\section{extremity trauma}

\author{
Benjamin T. Corona, PhD; ${ }^{1 *}$ Jessica C. Rivera, MD; $^{1} \mathrm{Johnny}$ G. Owens, MPT; ${ }^{2} \mathrm{Joseph}$. Wenke, PhD; ${ }^{1}$ Christopher \\ R. Rathbone, $\mathbf{P h D}^{\mathbf{1}}$ \\ ${ }^{1}$ Extremity Trauma and Regenerative Medicine, U.S. Army Institute of Surgical Research, Fort Sam Houston, TX; \\ ${ }^{2}$ Physical Therapy Service, Center for the Intrepid, San Antonio Military Medical Center, San Antonio, TX
}

\begin{abstract}
Extremity injuries comprise the majority of battlefield injuries and contribute the most to long-term disability of servicemembers. The purpose of this study was to better define the contribution of muscle deficits and volumetric muscle loss (VML) to the designation of long-term disability in order to better understand their effect on outcomes for limb-salvage patients. Medically retired servicemembers who sustained a combat-related type III open tibia fracture (Orthopedic cohort) were reviewed for results of their medical evaluation leading to discharge from military service. A cohort of battlefield-injured servicemembers (including those with nonorthopedic injuries) who were medically retired because of various injuries (General cohort) was also examined. Muscle conditions accounted for $65 \%$ of the disability of patients in the Orthopedic cohort. Among the General cohort, 92\% of the muscle conditions were identified as VML. VML is a condition that contributes significantly to long-term disability, and the development of therapies addressing VML has the potential to fill a significant void in orthopedic care.
\end{abstract}

Key words: battlefield, disability, extremity, function, injury, limb, regeneration, skeletal muscle, soft tissue, soldier, volumetric muscle loss.

\section{INTRODUCTION}

Trauma contributes substantially to the global burden of disease and injury; upwards of $\$ 400$ billion yearly (2010 data) in associated medical costs and loss of pro- ductivity in the United States have been reported [1]. Injuries primarily related to lacerations and multiple wounds account for $\sim 11$ percent of years lived with disability worldwide (2010 data) among all diseases and other conditions [2]. Likewise, the majority of injuries sustained in recent military conflicts (Operation Iraqi Freedom and Operation Enduring Freedom [OIF/OEF]) is to the extremities and often involves severe musculoskeletal injury [3-4]. These injuries are costly, both in terms of money spent on treatment and rehabilitation and also in terms of separation of highly trained personnel from the military [5-6]. Characterization of extremity injuries in OIF/OEF, including their impact on the ability of soldiers to return to duty, has highlighted the deleterious consequences of fractures on patient outcomes [3-7].

The clinical emphasis for the treatment of severe extremity trauma is on bone healing [8]. However, the fact that 82 percent of combat-related fractures are open

Abbreviations: $\mathrm{OEF}=$ Operation Enduring Freedom, OIF $=$ Operation Iraqi Freedom, PEB = U.S. Army Physical Evaluation Board, $\mathrm{VML}=$ volumetric muscle loss.

*Address all correspondence to Benjamin T. Corona, PhD; U.S. Army Institute of Surgical Research, 3698 Chambers Pass, Bldg 3611, JBSA, Fort Sam Houston, TX 78234; 210539-3459; fax: 210-539-3877.

Email: benjamin.t.corona.vol@mail.mil; corona.benjamin.t@gmail.com

http://dx.doi.org/10.1682/JRRD.2014.07.0165 
highlights the importance of soft-tissue repair for functional recovery of salvaged limbs [3]. In addition to open fractures, 53 percent of all extremity injuries are penetrating soft-tissue wounds [3], and "muscle conditions" rank high among the primary factors directly leading to partial disability from combat-related injuries [5]. That is, despite successful bone repair, which facilitates limb salvage, the residual muscle condition and associated functional deficiencies can contribute to chronic disability. These lingering muscle conditions are considered part of the natural sequelae of severe musculoskeletal trauma because there are currently no therapies available to the orthopedic surgeon to regenerate these extensive softtissue injuries. In order to develop effective therapies for such muscle conditions, it is critical to better understand the nature of these soft-tissue injuries.

While muscle conditions ubiquitously reference muscle injury of various etiology (e.g., strain, crush, and blast trauma), limited clinical reports [9] and our unpublished observations suggest that soft-tissue trauma and ensuing surgical care (e.g., fasciotomy and debridement) often culminate in volumetric muscle loss (VML) injury [10] - a traumatic or surgical frank loss of muscle tissue that cannot be endogenously regenerated and results in chronic loss of function. To this end, the primary purpose of this study was to determine the contribution of VML to service-disqualifying disability following battlefield trauma in patients. An Orthopedic cohort that had type III open tibia fractures was used to demonstrate that VML is a major cause of service-disqualifying disability in servicemembers with this injury. A General cohort of patients with both orthopedic and nonorthopedic injuries was included to put the magnitude and frequency of this disability condition in perspective and context of all wounding patterns.

\section{PATIENTS AND METHODS}

This study was conducted under a research protocol approved by the U.S. Army Medical Research and Materiel Command Institutional Review Board. The U.S. Army Physical Evaluation Board (PEB) consists of military and medical personnel who evaluate injured and ill servicemembers in order to determine their qualifications to continue Active Duty military service. The PEB can rule that an injured servicemember is adequately recovered to return to his or her military occupation or that he or she should be separated from the military or medically retired. The physical conditions that contribute to the inability of the medically retired to return to Active Duty are considered service disqualifying, disabling conditions. Each disabling condition is also considered by the PEB and assigned a percentage rating, which reflects to what degree that condition detracts from the servicemember's physical fitness. This percentage rating both reflects on a spectrum how disabled a servicemember is and corresponds with the disability payment for which he or she is eligible. The PEB designates conditions as service disqualifying and assigns the disability percentages by thorough review of the servicemember's medical documentation from various specialty providers. For example, a VML injury may be confirmed in the medical documentation by a physical therapist or orthopedic provider who, upon examining the servicemember, documents a persistent decrement in motor power or a frank defect in an injured muscle group. In the current study, the PEB results from two previously published studies [5-7] of wounded servicemembers were further examined for injury information and disability related to VML. VML was identified by documentation from a physical therapist or orthopedic provider of a motor weakness and/or frank loss of muscle tissue.

To evaluate the impact of VML on long-term servicedisqualifying disability in an orthopedic-specific population, the first cohort (Orthopedic cohort) consisted of patients with combat-related type III open tibia fractures sustained between 2003 and 2007 [7]. This cohort was composed of 123 servicemembers, 94 who were medically discharged from the military by the PEB for their leg injury [7]. PEB results for muscle conditions indicative of VML (documented muscle loss and persistent functional and/or strength deficit) were tallied to calculate the effect of VML on this orthopedic-specific population, both in disability and cost.

To determine the significance of VML in a population of battlefield-injured servicemembers medically retired for various reasons, including both orthopedic and nonorthopedic injuries, we examined an additional cohort (General cohort) that consisted of 450 wounded servicemembers who were medically evacuated from war between 2001 and 2005 and who eventually were all medically discharged because of their combat injuries [5]. Among these, 377 had at least one orthopedic-related disability. The PEB disability results were examined specifically for the 39 individuals with a muscle-related disabling condition [5]. The PEB record was examined to determine which of the 
muscle-disabling conditions corresponded with an injury resulting in VML. In both cohorts, the mechanism of injury, frequency of VML injury by anatomic region, and average percent disability per anatomic region were identiwere also tallied and used to calculate the projected lifetime disability cost caused by VML among this cohort using each subject's rank, base pay per rank, and projected life expectancy [11-12].

\section{RESULTS}

The demographic information of the soldiers medi-

\section{Table 1.}

Demographics and disability within two cohorts examined. General represents U.S. Army Physical Evaluation Board (PEB) results of patients medically retired because of various conditions. Orthopedic represents PEB results of patients medically retired because of type III tibia fractures.

\begin{tabular}{lcc}
\hline \multicolumn{1}{c}{ Variable } & Orthopedic & General \\
\hline Average Age (yr) & 25 & 26 \\
Male (\%) & 100 & 97 \\
Average Overall Disability & 50 & 55 \\
$\quad$ Rating (\%) & & \\
\hline \hline
\end{tabular}
fied. The percent disability and total disability from VML cally discharged in both cohorts is displayed in Table 1.

Examining the tibia fracture cohort (Orthopedic cohort), 23 individuals among the 94 medically retired servicemembers (24\%) had a muscle-related disability. Twenty subjects were injured by an explosion, while three sustained a gunshot wound. The average percent disability for all conditions was 50 percent; muscle conditions accounted for 65 percent of this group’s disability. Seven individuals were medically discharged solely because of their disabling muscle condition. Among the open fractures sustained, 7 were Gustilo and Anderson type IIIA, 15 were type IIIB, and 1 was type IIIC. In addition to the muscle loss sustained at the time of injury, 61 percent (14 of 23) of these subjects required a rotational muscle flap to achieve soft-tissue coverage for their fracture. As expected, the majority of the VML disabling conditions in this cohort were to the anterior and posterior compartment of the leg (Figure 1). The nature of the injury mechanism causes injuries to other regions of the lower limbs as well, which increases the challenges for the injured servicemembers to fully recover. The percent disability for each body region is displayed in Table 2 . Within the Orthopedic cohort, the average entitled lifetime disability payments for VML was $\$ 444,200$ USD per individual [12]. For this cohort of 23 patients, the sum cost for VML-related disability is a projected $\$ 10,125,500$ USD.

(\%)

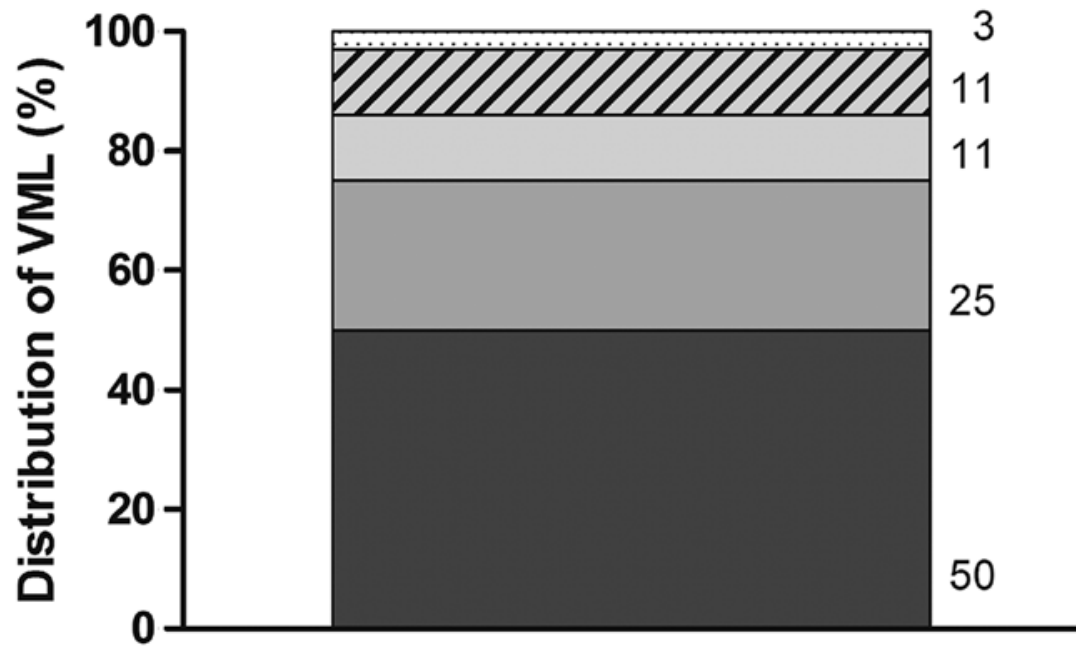

Gluteal and/or hip abductors ZZ Hamstrings $\square$ Quadriceps

$\square$ Leg, posterior compartment

Figure 1.

Distribution of volumetric muscle loss (VML) per body part for Orthopedic cohort (patients medically retired because of type III tibia fractures). 
Table 2.

Average percent disability granted per body part for Orthopedic cohort (patients medically retired because of type III tibia fractures) and General cohort (patients medically retired because of various conditions).

\begin{tabular}{lcc}
\hline \multirow{2}{*}{ Body Region } & \multicolumn{2}{c}{ Average Disability (\%) } \\
\cline { 2 - 3 } & Orthopedic & General \\
\hline Deltoid & - & 30 \\
Biceps/Triceps & - & 13 \\
Forearm Flexors/Extensors & - & 22 \\
Gluteal and/or Hip Abductors & 13 & 40 \\
Hamstrings & 40 & 37 \\
Quadriceps & 33 & 26 \\
Leg, Posterior Compartment & 21 & 26 \\
Leg, Anterior Compartment & 28 & 20 \\
\hline \hline
\end{tabular}

The average overall disability rating for the cohort of patients in the general wound population was 55 percent. Of 450, 39 individuals were previously reported to have been medically discharged because of a muscle-related disabling condition [5]. Of these, 36 (92\%) had confirmed volumetric loss to a major muscle group and/or residual muscle weakness. For those with a muscle condition, the muscle condition accounted for 53 percent of their total disability. Thirty of these were injured by an explosion, while the remaining six were injured by a gunshot wound. Sixty-seven percent of the VML injuries were to the lower limbs (quadriceps leg, posterior and anterior compartments, gluteal and/or hip abductors, or hamstrings) (Figure 2). The average percent disability granted per body region is displayed in Table 2. Fiftyeight percent $(n=21)$ of individuals also had a fracture, 14 percent $(n=5)$ had a concomitant nerve injury, and 5 percent $(n=2)$ sustained a concomitant vascular injury in the limb with the VML. The VML was associated with a painful scar, which in itself received a disability rating in 17 percent $(n=6)$ of subjects. The projected lifetime disability costs for those with VML in the general disability population is on average $\$ 341,300$ USD per individual [12]. This indicates that each of these 36 individuals is entitled to disability payments over their projected life span of this amount solely because of their muscle-related disability. For this small cohort of 36 patients, the projected lifetime disability cost for VML totals \$12,286,000 USD.

\section{DISCUSSION}

The documentation of patient outcomes following severe trauma during times of war has revealed that a large number of injuries that occur subsequent to trauma are to the extremities [3,5-6], which is crucial information to better understand how to improve outcomes for wounded servicemembers that also may translate to

(\%)

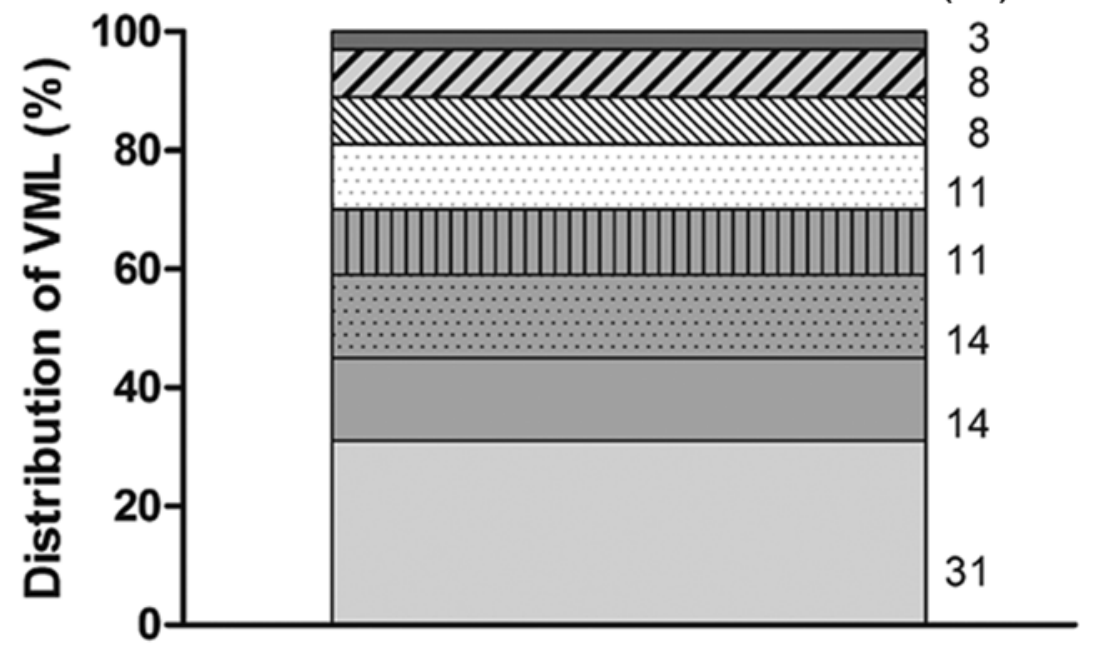

$\square$ Leg, anterior compartment ZD Hamstrings Deltoid 6 Gluteal and/or hip abductors 미 Biceps/triceps F.... Forearm flexors/extensors $\square$ Leg, posterior compartment $\square$ Quadriceps

Figure 2.

Distribution of volumetric muscle loss (VML) per body part for General cohort (patients medically retired because of various conditions). 
improved care for civilian trauma patients. Despite the large number of musculoskeletal extremity injuries incurred following trauma in both the civilian and military population, the nature of the soft-tissue injury and its effect on patient disability is largely undefined. More specifically, the extent to which VML directly contributes to disability in those with orthopedic-specific conditions (type III tibia fracture) was not known. To address this knowledge gap, we examined muscle conditions within a population of servicemembers that was discharged specifically for a type III open tibia fracture (Orthopedic cohort). To evaluate the overall effect of VML in a population of servicemembers retired for various reasons, we examined muscle conditions leading to permanent disability that were primarily identified as VML injury. Musclerelated conditions (i.e., VML) contributed 65 percent to the permanent disability in the type III open tibia fracture cohort. VML was responsible for disability in 8 percent of the patients (36 of 450), even when including patients medically retired for various reasons. Collectively, given the large contribution of muscle-related conditions and hence VML to permanent disability, these data highlight the deleterious effect of chronic muscle impairment on long-term patient outcomes.

Based on the frequency of orthopedic injuries from combat [3-4] and the large contribution of VML to disability, the treatment of VML has the potential to improve outcomes for a large number of patients. However, it is important to take into consideration the inherent limitations of using the retrospective PEB data to qualify the impact of VML. Given the paucity of available data regarding VML, it is currently not possible to correlate the degree of functional loss to a given disability rating. The PEB also designates conditions that are service disqualifying, which may or not may equate to actual disability or any functional limitation outside of the demands of military service. There may be other tissues injured, such as nerves, that contribute to the muscle-related disability. Unfortunately, the extent of the contribution of nerve injury is difficult to ascertain based on our current data. That being said, it is important to point out that VML was also objectively identified by a documented loss of skeletal muscle. Another factor that may have affected the impact of VML on disability is the potential for amputation; given that some of the patients in both cohorts may have undergone elective amputation due to infectious complications and bone nonunion, it is possible that the current findings may in fact be an under- estimation of the true cost of VML. Nonetheless, more than 14,500 servicemembers have been evacuated as a result of battle injuries [13-14]. A percentage of those will be medically retired, and based on the results of the current study, a significant percentage of those will have VML. It is also important to consider the contribution of VML to other orthopedic-related injuries. For example, the impact of muscle weakness due to VML on osteoarthritis was not specifically examined [9]. However, it is logical to speculate that an alteration in gait and joint loading has the potential to exacerbate symptoms of osteoarthritis [15]. Although the current data highlight the direct impact of VML disability, its indirect effect on other comorbidities such as joint pathology remains unknown. Lastly, the prevalence of VML injury that is not documented as relating to a debilitating condition by the PEB but may negatively affect physical activity, return to duty, and quality of life remains undefined.

Despite a tremendous amount of attention given to bone healing after type III open tibia fracture, based on the current findings it is appropriate to conclude that soft-tissue complications make the majority contribution to disability of salvaged limbs. The finding that 50 percent of the fracture cohort had a VML localized to the anterior compartment is intuitive given the nature of the cohort examined. However, it is interesting to note that although this cohort was evaluated based on evacuation due to tibia fracture, the remaining percent distribution was accounted for by VML injuries in other muscle regions, which included 25 percent in the posterior compartment. Whether this is specifically associated with donor site morbidity resulting from flap coverage was not examined in this study; however, another logical possibility is that this is a reflection of explosion injury to multiple muscles.

A common treatment course following severe extremity injury in servicemembers may involve an initial coverage of bone with a free or rotational muscle flap. While rotational muscle flaps may succeed in providing soft-tissue coverage (e.g., rotational gastrocnemius muscle flap to cover an exposed tibia), they do not restore strength of the underlying traumatized musculature and may result in donor site morbidity. An unfortunate consequence may be the creation of a VML injury. In such a situation, orthopedic strategies are available to improve bone healing; however, the therapies available for treating the VML are lacking. For example, the use of a ringed external fixator and distraction osteogenesis are strategies at a surgeon's disposal, but even after bone healing and substantial rehabilitation, significant deficits in 
the functioning limb may persist because of the muscle injury. Patients may choose to avoid amputation with the use of an energy-storing orthosis (e.g., Intrepid Dynamic Exoskeletal Orthosis; $\mathrm{IDEO}^{\mathrm{TM}}$ ) [16], which will be a permanent assistive device requiring maintenance and replacements through the military or civilian system. Unfortunately, even with the highly effective orthotic, patients' physical activity levels cannot be returned to full function. For many others for whom the VML is not in the lower leg, the orthotic device is not applicable.

Understanding the severity and nature of muscle injuries following severe limb trauma is important to the development of effective therapies. Human skeletal muscle possesses a remarkable ability to repair and regenerate following moderately severe injury [17-18]; the remaining soft-tissue envelope and the critical elements within it (e.g., basal lamina and satellite cells) remain intact enabling an appropriate myogenic and immunogenic response [19]. For these injuries, adjunct therapies (e.g., growth factor delivery or immune modulation) may be appropriate to restore or enhance the endogenous regenerative response. An important distinction is drawn, however, when considering a frank loss of skeletal muscle, i.e., VML injury, in which all endogenous regenerative elements are absent from the defect area. It is critical to take this difference into account when developing strategies for VML repair, i.e., therapies effective for injuries in which the overall architecture is intact may be inadequate for VML.

The precise relationship between the magnitude and geometry of VML and the resultant degree of functional impairment has not been determined. To date, a total of eight VML cases have been reported among four studies [9,20-22], but standardized assessments of VML magnitude and strength loss or disability are not consistently provided. Complicating the distinction of debilitating VML are the unique characteristics of various muscle units (e.g., quadriceps vs anterior tibialis muscles) and their recruitment during daily living and work activities. Preclinical models of VML reliably indicate that a relatively small VML (10\%-20\% loss of muscle) can result in a disproportionately large strength deficit (30\%-90\%) [23-24], suggesting that disabling conditions may result from a lower threshold of muscle loss than expected. The data available for the current study are limited to information within the medical record, which did not include dimensions or magnitudes of volume loss; the documented VML injuries were likely large because of their visual distinction during patient assessments. Although the specific characteristics of VML (i.e., amount of muscle loss) likely varied among patients within each cohort and the degree of VML injury (i.e., extent of functional impairment) could not be documented, the overall conclusion that VML contributes to disability is still supported. Prospective investigations are warranted and necessary to predict functional loss and potential disability per VML injury characteristics. The study of VML is still relatively new; a better understanding of these objective criteria of VML will undoubtedly improve a clinician's ability to improve patient care.

\section{CONCLUSIONS}

The major findings are that in an orthopedic-specific population (limb salvage type III tibia fracture) muscle conditions (VML) account for 65 percent of disability and failing to adequately address soft-tissue deficits results in persistent muscle weakness that plays a large part in poor outcomes following injury. VML contributes to $>90$ percent of muscle conditions that lead to longterm disability when considering patients who have been medically retired because of various injuries. The impact of VML on the general population is significant when one considers that muscle conditions rank among the top 10 most frequent unfitting conditions [5]. Decades of ground-breaking research have provided clinicians with therapeutic options for the treatment of bone complications. It is crucial to direct efforts toward the treatment of muscle deficits that follow successful bone repair. Given the large contribution of VML to these muscle deficits and the unique etiology of VML, it is imperative to specifically address this type of injury to improve outcomes for a large number of patients. This information is important to the orthopedic researcher and basic and translational scientist for the development of appropriate therapies and will aid with informing funding initiatives.

\section{ACKNOWLEDGMENTS}

\section{Author Contributions:}

Study concept and design: B. T. Corona, J. C. Rivera, J. G. Owens, J. C. Wenke, C. R. Rathbone.

Acquisition of data: J. C. Rivera, J. G. Owens.

Analysis and interpretation of data: B. T. Corona, J. C. Rivera, J. G. Owens, J. C. Wenke, C. R. Rathbone. 
Drafting of manuscript: B. T. Corona, J. C. Rivera, C. R. Rathbone. Critical revision of the manuscript for important intellectual content: B. T. Corona, J. C. Rivera, J. G. Owens, J. C. Wenke, C. R. Rathbone. Obtained funding: B. T. Corona, J. C. Wenke, C. R. Rathbone.

Financial Disclosures: The authors have declared that no competing interests exist.

Funding/Support: This material was based on work supported by the U.S. Army Medical Research and Materiel Command of the Department of Defense.

Additional Contributions: Dr. Rathbone is now affiliated with Arteriocyte Inc, Cleveland, Ohio. Mr. Owens is now affiliated with the Clinical Research Center, San Antonio Military Medical Center, San Antonio, Texas.

Institutional Review: This study was conducted under a research protocol approved by the U.S. Army Medical Research and Materiel Command Institutional Review Board.

Participant Follow-Up: The authors have no plans to notify the study subjects of the publication of this article because of a lack of contact information.

Disclaimer: The opinions or assertions contained herein are the private views of the authors and are not to be construed as official or as reflecting the views of the Department of the Army or the Department of Defense.

\section{REFERENCES}

1. Corso P, Finkelstein E, Miller T, Fiebelkorn I, Zaloshnja E. Incidence and lifetime costs of injuries in the United States. Inj Prev. 2006;12(4):212-18. [PMID:16887941] http://dx.doi.org/10.1136/ip.2005.010983

2. Vos T, Flaxman AD, Naghavi M, Lozano R, Michaud C, Ezzati M, et al. Years lived with disability (YLDs) for 1160 sequelae of 289 diseases and injuries 1990-2010: A systematic analysis for the Global Burden of Disease Study 2010. Lancet. 2012;380(9859):2163-96. [PMID:23245607]

3. Owens BD, Kragh JF Jr, Macaitis J, Svoboda SJ, Wenke JC. Characterization of extremity wounds in Operation Iraqi Freedom and Operation Enduring Freedom. J Orthop Trauma. 2007;21(4):254-57. [PMID:17414553] http://dx.doi.org/10.1097/BOT.0b013e31802f78fb

4. Owens BD, Kragh JF Jr, Wenke JC, Macaitis J, Wade CE, Holcomb JB. Combat wounds in Operation Iraqi Freedom and Operation Enduring Freedom. J Trauma. 2008;64(2): 295-99. [PMID:18301189] http://dx.doi.org/10.1097/TA.0b013e318163b875

5. Cross JD, Ficke JR, Hsu JR, Masini BD, Wenke JC. Battlefield orthopaedic injuries cause the majority of long-term disabilities. J Am Acad Orthop Surg. 2011;19(Suppl 1):S1-7. [PMID:21304041]

6. Masini BD, Waterman SM, Wenke JC, Owens BD, Hsu JR, Ficke JR. Resource utilization and disability outcome assessment of combat casualties from Operation Iraqi Free- dom and Operation Enduring Freedom. J Orthop Trauma. 2009;23(4):261-66. [PMID:19318869] http://dx.doi.org/10.1097/BOT.0b013e31819dfa04

7. Cross JD, Stinner DJ, Burns TC, Wenke JC, Hsu JR; Skeletal Trauma Research Consortium (STReC). Return to duty after type III open tibia fracture. J Orthop Trauma. 2012; 26(1):43-47. [PMID:21885998] http://dx.doi.org/10.1097/BOT.0b013e31821c0ec1

8. Cierny G 3rd, Byrd HS, Jones RE. Primary versus delayed soft tissue coverage for severe open tibial fractures. A comparison of results. Clin Orthop Relat Res. 1983;(178):54-63. [PMID:6349899]

9. Mase VJ Jr, Hsu JR, Wolf SE, Wenke JC, Baer DG, Owens J, Badylak SF, Walters TJ. Clinical application of an acellular biologic scaffold for surgical repair of a large, traumatic quadriceps femoris muscle defect. Orthopedics. 2010; 33(7):511. [PMID:20608620]

10. Grogan BF, Hsu JR; Skeletal Trauma Research Consortium. Volumetric muscle loss. J Am Acad Orthop Surg. 2011;19(Suppl 1):S35-37. [PMID:21304045]

11. Arias E. National Vital Statistics Reports. Vol 61 [Internet]. Atlanta (GA): Centers for Disease Control and Prevention; 2012 Sep [cited 2014 Feb]. Available from: http://www.cdc.gov/nchs/data/nvsr/nvsr61/nvsr61_03.pdf

12. DFAS. Military Basic Pay Chart. January 1, 2014 [Internet]. Washington (DC): DFAS; 2014 Dec [cited 2014 Feb]. Available from:

http://www.dfas.mil/militarymembers/payentitlements/military-pay-charts.html

13. Armed Forces Health Surveillance Center (AFHSC). Medical evacuations from Afghanistan during Operation Enduring Freedom, active and reserve components, U.S. Armed Forces, 7 October 2001-31 December 2012. MSMR. 2013;20(6):2-8. [PMID:23819534]

14. Armed Forces Health Surveillance Center (AFHSC). Medical evacuations from Operation Iraqi Freedom/Operation New Dawn, active and reserve components, U.S. Armed Forces, 2003-2011. MSMR. 2012;19(2):18-21.

[PMID:22372753]

15. Tourville TW, Jarrell KM, Naud S, Slauterbeck JR, Johnson RJ, Beynnon BD. Relationship between isokinetic strength and tibiofemoral joint space width changes after anterior cruciate ligament reconstruction. Am J Sports Med. 2014;42(2):302-11. [PMID:24275860] http://dx.doi.org/10.1177/0363546513510672

16. Patzkowski JC, Blanck RV, Owens JG, Wilken JM, Kirk KL, Wenke JC, Hsu JR; Skeletal Trauma Research Consortium. Comparative effect of orthosis design on functional performance. J Bone Joint Surg Am. 2012;94(6):507-15. [PMID:22437999] http://dx.doi.org/10.2106/JBJS.K.00254 
17. Hart AJ, Hodgson WC, Scott-Davey T, Harris JB. Neuromuscular toxicology of the venom of Collett's snake (Pseudechis colletti): A histopathological study. Muscle Nerve. 2011;43(4):552-59. [PMID:21305571] http://dx.doi.org/10.1002/mus.21916

18. Sanfilippo JL, Silder A, Sherry MA, Tuite MJ, Heiderscheit BC. Hamstring strength and morphology progression after return to sport from injury. Med Sci Sports Exerc. 2013;45(3):448-54. [PMID:23059864] http://dx.doi.org/10.1249/MSS.0b013e3182776eff

19. Tidball JG, Villalta SA. Regulatory interactions between muscle and the immune system during muscle regeneration. Am J Physiol Regul Integr Comp Physiol. 2010; 298(5):R1173-87. [PMID:20219869]

http://dx.doi.org/10.1152/ajpregu.00735.2009

20. Garg K, Ward CL, Hurtgen BJ, Wilken JM, Stinner DJ, Wenke JC, Owens JG, Corona BT. Volumetric muscle loss: Persistent functional deficits beyond frank loss of tissue. J Orthop Res. 2015;33(1):40-46. [PMID:25231205]

21. Gentile NE, Stearns KM, Brown EH, Rubin JP, Boninger ML, Dearth CL, Ambrosio F, Badylak SF. Targeted rehabilitation after extracellular matrix scaffold transplantation for the treatment of volumetric muscle loss. Am J Phys Med Rehabil. 2014;93(11, Suppl 3):S79-87. [PMID:25133624] http://dx.doi.org/10.1097/PHM.0000000000000145

22. Sicari BM, Rubin JP, Dearth CL, Wolf MT, Ambrosio F, Boninger M, Turner NJ, Weber DJ, Simpson TW, Wyse A, Brown EH, Dziki JL, Fisher LE, Brown S, Badylak SF. An acellular biologic scaffold promotes skeletal muscle forma- tion in mice and humans with volumetric muscle loss. Sci Transl Med. 2014;6(234):234ra58. [PMID:24786326]

http://dx.doi.org/10.1126/scitranslmed.3008085

23. Corona BT, Garg K, Ward CL, McDaniel JS, Walters TJ, Rathbone CR. Autologous minced muscle grafts: A tissue engineering therapy for the volumetric loss of skeletal muscle. Am J Physiol Cell Physiol. 2013;305(7):C761-75. [PMID:23885064] http://dx.doi.org/10.1152/ajpcell.00189.2013

24. Li MT, Willett NJ, Uhrig BA, Guldberg RE, Warren GL. Functional analysis of limb recovery following autograft treatment of volumetric muscle loss in the quadriceps femoris. J Biomech. 2014;47(9):2013-21. [PMID:24280565] http://dx.doi.org/10.1016/j.jbiomech.2013.10.057

Submitted for publication July 16, 2014. Accepted in revised form July 1, 2015.

This article and any supplementary material should be cited as follows:

Corona BT, Rivera JC, Owens JG, Wenke JC, Rathbone CR. Volumetric muscle loss leads to permanent disability following extremity trauma. J Rehabil Res Dev. 2015; 52(7):785-92.

http://dx.doi.org/10.1682/JRRD.2014.07.0165

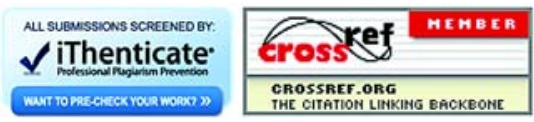

